\title{
Congenital hypothyroidism in Indian preterm babies - screening, prevalence, and aetiology
}

Wrodzona niedoczynność tarczycy u indyjskich wcześniaków - badania przesiewowe, częstość występowania i etiologia

\author{
${ }^{1}$ Hemchand Krishna Prasad, ${ }^{2}$ Poornima Pulluru, ${ }^{2}$ Lakshmi Venugopalan, ${ }^{2}$ Gnanabalan Murugesan, \\ 2Shanmughasundaram Ramanathan
}

${ }^{1}$ Department of Pediatric Endocrinology, Mehta Multispeciality Hospitals India Pvt Ltd, India

${ }^{2}$ Department of Neonatology, Mehta Multispeciality Hospitals India Pvt, India

\begin{abstract}
Introduction: Paucity of data on hypothyroidism in Indian preterms.

Aim of the study: To describe the prevalence, aetiology, and experience with screening for primary hypothyroidism in preterm babies Material and methods: A prospective observational study conducted for 3 years in a tertiary care unit, where all babies born $<37$ weeks screened by heel prick for Thyroid Stimulating Hormone (TSH) were included. All screen positive cases (TSH $\geq 6 \mu \mathrm{IU} / \mathrm{ml}) \mathrm{underwent}$ venous testing immediately; venous TSH $\geq 20$ or Free T4 $<0.9 \mathrm{ng} / \mathrm{dl}$ was considered as confirmed positive. All babies underwent venous testing at term. Etiological testing was performed where feasible. Confirmed cases were initiated on thyroxine therapy and followed up.

Results: 1167 preterm babies presented during the study period. 1147 (98\%) underwent TSH screening and 17 (1.4\%) were screen positive; 15 babies underwent confirmatory venous test. Of these 15 babies, 2 were confirmed and started on therapy. The remaining 13 babies underwent retest venous sample at term, and 8 of these were confirmed cases. Of the screen-negative babies, $94 \%$ underwent repeat venous testing at term/ prior to discharge. Five were confirmed to have congenital hypothyroidism. Thus, the prevalence of congenital hypothyroidism was 1 in 77 preterm babies. No correlation was observed between screening TSH and venous TSH $(p>0.05)$. Aetiological evaluation in 8 babies revealed secondary to maternal antibody in 4 cases (50\%) and permanent thyroid defects in 4 cases (50\%).
\end{abstract}

Conclusions: We observed a high prevalence (1 in 77), need for repeat venous testing, irrespective of initial screening, and significant permanent congenital hypothyroidism (50\%) in our series.

Key words:

preterm, congenital hypothyroidism, screening, retesting.

\section{Introduction}

The incidence of congenital hypothyroidism in Indian babies is reported to be 1 in 600 (Eastern India); 1 in 727 (Southern India); 1 in 3400 (Chandigarh); 1 in 1140 (Lucknow) from North India; and 1 in 1700 (Hyderabad), which is much higher than the reported incidence from western literature of 1 in 3500 [1-6]. There are few data on congenital hypothyroidism in preterm babies. The physiological immaturity of the axis, the low maternal contribution, illnesses, and drugs have variable influences on the thyroid functional status $[7,8]$. The pivotal question, whether the prevalence of congenital hypothyroidism is higher in preterms, is debatable. Extensive previous research reveals both comparable $[9,10]$ and higher prevalence [11-13] compared to term babies. The variable results may be due to the different study populations and varied cut-offs used in various studies.

Conventionally, preterm babies are suspected to be more prone to transient congenital hypothyroidism because of perinatal factors [14]. However, recent research has identified a significant presence of permanent hypothyroidism in preterm babies [15]. This has pertinent implications for the counselling of the families at the time of initiation of thyroxine therapy in the neonatal period.

Screening for congenital hypothyroidism in preterm babies is a classic case of double whammy. On the one hand there is a risk of missing cases of congenital hypothyroidism owing to immaturity of the hypothalamo-pituitary thyroid axis. On the other hand there is a risk of overdiagnosing cases of congeni- 
tal hypothyroidism due to physiological alterations in the HPT axis [16]. The interpretation of thyroid function test in a preterm baby must be done carefully.

The need for a second thyroid function test in these babies is debatable. Several studies have supported the need for a venous sample at term or 36 weeks post menstrual age to increase the sensitivity of pick-up [11, 12, 15-17]. There are also studies that quote no added value of a repeat test as long as the initial cut-off of TSH is low [13]. There are no Indian data in this regard.

With this background, we performed this study to ascertain the prevalence of congenital hypothyroidism in preterm babies in our unit, present their aetiological profile and ascertain the utility of a repeat venous testing in preterm babies.

\section{Material and methods}

We conducted a prospective observational study over a period of 3 years (2015-2018).

From amongst all babies either delivered at, or referred to, a tertiary care centre in South India, we included babies born $<37$ weeks of gestation. We excluded babies with Down syndrome, death, or against medical advice, those who were transfused prior to sampling, and those who could not be screened for congenital hypothyroidism. Sample was collected at 72-120 hours of life, irrespective of gestational age, by heel prick by a single trained technician in pre-marked circles of $1 \mathrm{~cm}$ diameter on Schleiecher and Schuell specimen collection filter paper. The filter papers were air dried and transported, and TSH levels were estimated by Sandwich Enzyme Linked Immunoassay using Bio-rad Quantase TM kit (lower detection limit: $0.05 \mu \mathrm{lU} / \mathrm{mL}$ and upper detection limit: $100 \mu \mathrm{lU} / \mathrm{ml}$ ).
The gestational age, sex, and heel prick TSH were collected prospectively. Data pertaining to maternal (age, hypertension, diabetes mellitus, hypothyroidism), perinatal factors (mode of delivery), and neonatal factors (birth weight, sex, gestational age, presence of neonatal complications) were collected and entered.

The study protocol is described in Fig. $1[18,19]$. All screenpositive cases underwent venous testing immediately. We considered heel prick $\mathrm{TSH} \geq 6 \mu \mathrm{lU} / \mathrm{ml}$ as screen positive; those with venous $\mathrm{TSH} \geq 20$ or free $\mathrm{T} 4<0.9 \mathrm{ng} / \mathrm{dl}$ at $\mathrm{GA}<37$ weeks or venous $\mathrm{TSH} \geq 10$ or Free $\mathrm{T} 4<0.9 \mathrm{ng} / \mathrm{dl}$ in a term infant as confirmed positive. However, those with screen positive and venous $\mathrm{TSH}<20$ and Free T4 $>0.9$ ng/dl were followed up and retested by a venous sample for Free T4 and TSH at term. All screen-negative cases also underwent venous testing at term. Babies with congenital hypothyroidism were evaluated and with Anti-thyroid peroxidase antibody, anti-thyroglobulin antibody, ultrasound of the thyroid, and technetium thyroid scintigraphy, where feasible. They were initiated on thyroxine therapy in a dose of 10-15 $\mu \mathrm{g} /$ $\mathrm{kg} /$ day. Subsequently, these babies were followed up in the thyroid clinic every 2 weeks until TSH normalized, twice monthly in the first year of life and thrice monthly thereafter $[18,19]$. Study was approved by the Institute Ethics Committee. Collected data were entered in Microsoft Excel and analysed. All data were presented as mean $\pm \mathrm{SD}$. Pearson correlation was used to determine the correlation between screening and venous TSH.

\section{Results}

A total of 1167 preterm babies presented at our unit during the study period, of whom 1147 (98\%) underwent TSH scre-

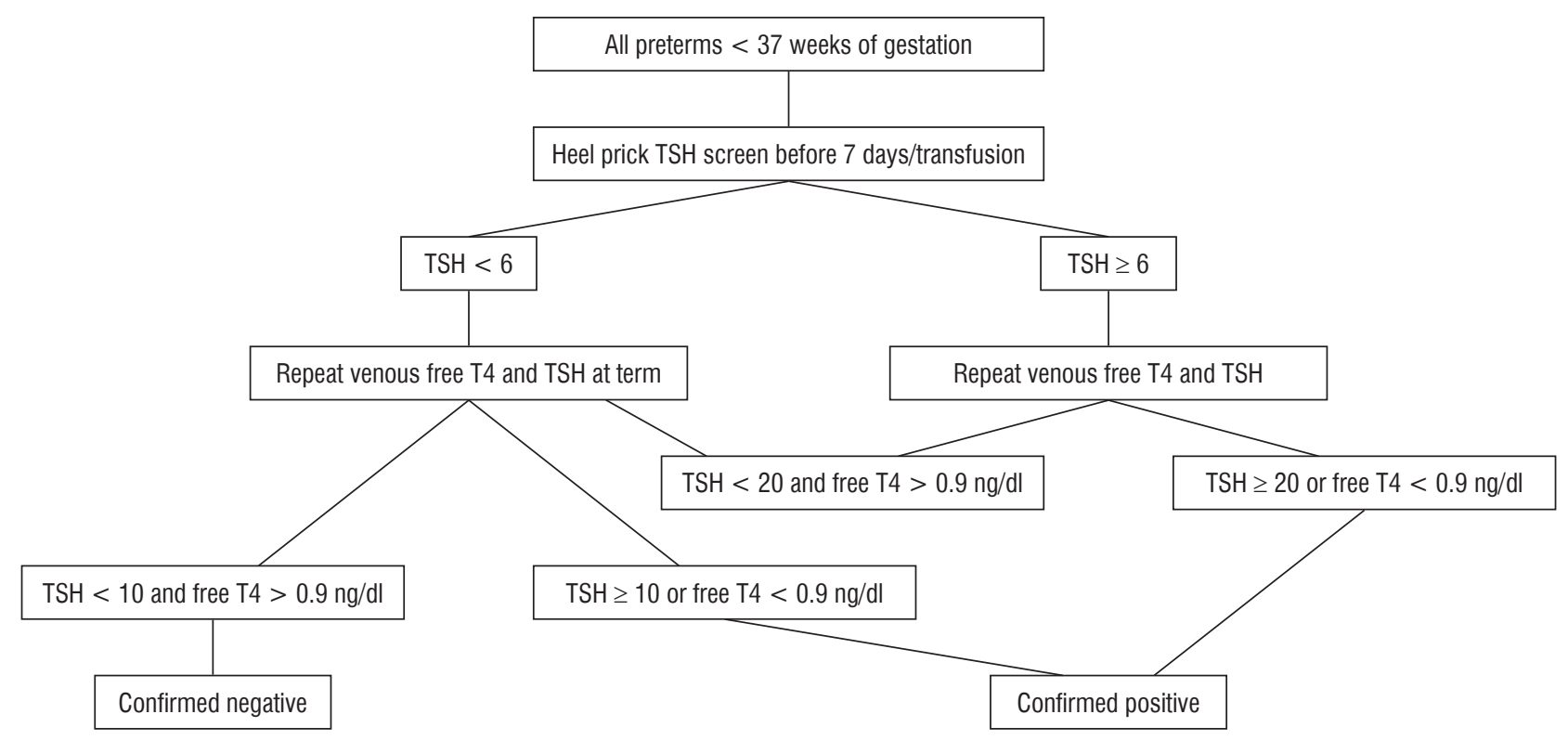

Figure 1. Study protocol 
Table I. Screening thyroid stimulating hormone (TSH) at different gestational ages in the study population

\begin{tabular}{ll}
\hline Gestational age (in weeks) & TSH values (in $\mu \mathrm{UU} / \mathrm{ml})$ \\
\hline 28 weeks & $2.0 \pm 0.5$ \\
\hline 29 weeks & $1.9 \pm 0.7$ \\
\hline 30 weeks & $2.0 \pm 0.6$ \\
\hline 31 weeks & $2.1 \pm 0.8$ \\
\hline 32 weeks & $2.1 \pm 0.8$ \\
\hline 33 weeks & $1.7 \pm 0.7$ \\
\hline 35 weeks & $1.8 \pm 0.7$ \\
\hline 36 weeks & $2.0 \pm 0.5$ \\
\hline
\end{tabular}

ening. The mean \pm SD of TSH at different gestational ages are described in Table 1. Of the 1147 preterm babies, 17 (1.4\%) were screen positive. A comparison of the maternal (age, hypertension, diabetes mellitus, hypothyroidism), perinatal (mode of delivery), and neonatal factors (birth weight, sex, gestational age, presence of neonatal complications) between the preterm babies with and without positive screening for congenital hypothyroidism is depicted in Table 2.

Out of these 17 babies who were screen positive, 15 underwent confirmatory venous test: Two were confirmed to have congenital hypothyroidism as preterm babies. The remaining 13 babies underwent retest venous sample at term, and 8 of these were confirmed to have and 5 not to have congenital hypothyroidism. Of the screen-negative babies, 1100 underwent repeat venous testing at term/ prior to discharge. Five out of these 1100 babies were confirmed to have congenital hypothyroidism. Thus, 15 babies out of 1147 screened babies were found to have congenital hypothyroidism (Fig. 2) leading to a prevalence of 1 in 77 screened babies. We attempted to study the correlation between neonatal TSH screen and venous $\mathrm{TSH}$ in the study population. No correlation was observed between screening TSH and venous TSH $(p>0.05)$.

None of the preterm babies with congenital hypothyroidism had clinical signs or symptoms of congenital hypothyroidism. Out of the 15 cases of congenital hypothyroidism, evaluation was feasible in 8 cases. Aetiological evaluation revealed transient causes secondary to maternal antibody in 4 cases $(50 \%)$ and permanent thyroid defects in 4 cases (50\%). Permanent thyroid defects observed in the study include dyshormonogenesis $(n=2)$, agenesis $(n=1)$, and ectopic lingual thyroid $(n=1)$.

All babies with confirmed hypothyroidism were initiated on thyroxine replacement in a dose of $10-15 \mu \mathrm{g} / \mathrm{kg}$ (mean dose $11.5 \pm 1.1 \mu \mathrm{g} / \mathrm{kg} /$ day) and followed up in the thyroid clinic.
Table II. Comparison of maternal, perinatal, and neonatal factors in preterm babies who were screen positive and screen negative

\begin{tabular}{|c|c|c|}
\hline & $\begin{array}{l}\text { Screen positive } \\
\text { for congenital } \\
\text { hypothyroidism } \\
(n=17)\end{array}$ & $\begin{array}{l}\text { Screen negative } \\
\text { for congenital } \\
\text { hypothyroidism } \\
(n=1130)\end{array}$ \\
\hline Maternal PIH & $3(17.6 \%)$ & $183(16 \%)$ \\
\hline Maternal diabetes & $4(23.4 \%)$ & 229 (20\%) \\
\hline $\begin{array}{l}\text { Maternal } \\
\text { hypothyroidism }\end{array}$ & $4(23.4 \%)$ & 206 (18\%) \\
\hline \multicolumn{3}{|l|}{ Mode of delivery } \\
\hline Normal & $17.6 \%$ & $15 \%$ \\
\hline $\begin{array}{l}\text { Caesarean } \\
\text { section }\end{array}$ & $63.4 \%$ & $66 \%$ \\
\hline $\begin{array}{l}\text { Instrumental } \\
\text { delivery }\end{array}$ & $17.6 \%$ & $19 \%$ \\
\hline Birth weight (kg) & $\begin{array}{l}2.2 \pm 0.9 \\
(0.6-3.8)\end{array}$ & $\begin{array}{l}2.1 \pm 0.8 \\
(0.7-3.8)\end{array}$ \\
\hline $\mathrm{M}$ : F ratio & $1.2: 1$ & $1.3: 1$ \\
\hline Presence of RDS & $4(23.4 \%)$ & 298 (26\%) \\
\hline $\begin{array}{l}\text { Requirement for } \\
\text { surfactant }\end{array}$ & $3(17.6 \%)$ & $172(15 \%)$ \\
\hline Presence of NNEC & $2(11.7 \%)$ & 57 (5\%) \\
\hline Presence of PDA & $1(5.8 \%)$ & $57(5 \%)$ \\
\hline Twin gestation & $2(11.7 \%)$ & $48(4 \%)$ \\
\hline
\end{tabular}

\section{Discussion}

To the best of the author's knowledge, this is the first Indian study on congenital hypothyroidism in preterm babies. We have described the experience of our unit in screening and evaluating preterm babies with congenital hypothyroidism. In the present study, we have observed a prevalence of 1 in 77 among the 1147 preterm babies screened. Five (33\%) out of these cases were missed on initial screening, reiterating the need for repeat testing, and 5 of the screen-positive cases did not have the disease, reiterating the need to follow the standard protocols in preterm babies

In our study, we have 15 cases of confirmed congenital hypothyroidism out of 1147 screened preterms, resulting in a prevalence of 1 in 77 . This prevalence is much higher than term babies. Our results are comparable to reports by Silva et al. [20], Tylek et al. [11], Bijamia et al. [12], and Korada et al. [13], who reported a prevalence of 1 in 242, 1 in 202, 1 in 128, 


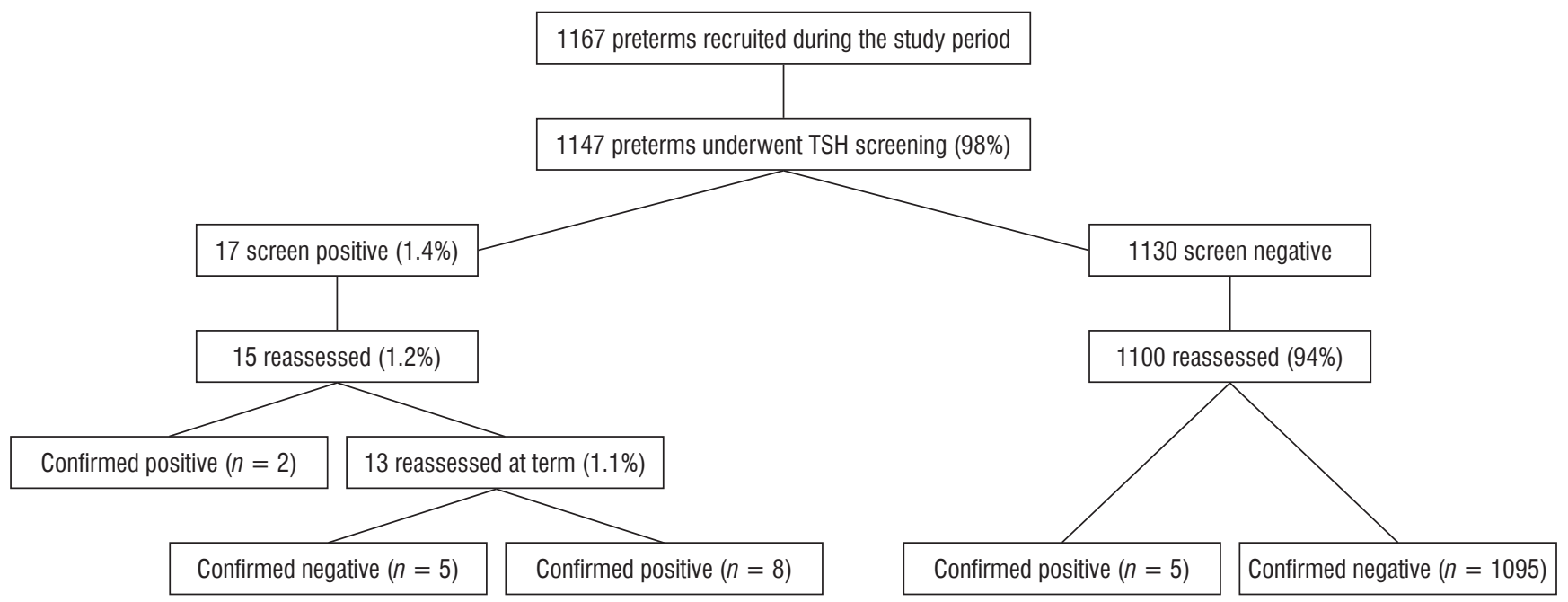

Figure 2. Results of the study

and 1 in 560, respectively. However, Srinivasan et al. [9] and Mao et al. [10] did not report a similar increase. This may be attributable to the fact that these tests have been done on healthy babies, but ours is a tertiary referral unit where many high-risk babies are seen. The influence of perinatal risk factors on increased prevalence of $\mathrm{CH}$ has been described previously [21]. Also, a significant number of our preterms underwent interventions like surfactant administration, enterocolitis, and ductus closure in the first week of life (Table II). However, the high prevalence in preterm babies in our study is an indication to screen all preterm babies for congenital hypothyroidism.

In our study, we evaluated 8 out of the 15 confirmed cases; $50 \%$ each were transient and permanent aetiologies. The other studies have quoted $60 \%, 45.4 \%$, and $40 \%$ permanent aetiologies for congenital hypothyroidism in preterm babies $[9,11,15]$. The variability may be attributable to the different definitions adopted in various studies for permanency: Srinivasan et al. [9] defined requirement of thyroxine beyond 3 years as permanent. We have adopted universally acceptable scintigraphic evidence to determine permanent congenital hypothyroidism. Notwithstanding, the high prevalence of permanent congenital hypothyroidism suggests that aetiological evaluation is mandatory in these high-risk babies, either at birth or at 3 years of age.

Five cases of congenital hypothyroidism had normal initial TSH screen. These cases would have been missed if the TSH screening was not repeated at term. Similarly, Silva et al. [20], Bijamia et al. [12], and Vigone et al. [15] reported that $90.9 \%$, $88.8 \%$, and $73.9 \%$ of the cases would have been missed if the initial screening were not repeated. This may be attributable to the neonatal illnesses in a preterm baby, which may lead to suppression of the HPT axis. Considering the importance of early therapy for congenital hypothyroidism, it is essential that all preterms are retested at term or prior to discharge, irrespective of the initial thyroid screening results.

The Indian Society of Paediatric and Adolescent Endocrinology (ISPAE) have given guidelines for management of congenital hypothyroidism $[22,23]$. However, we used the guidelines recommended by the ESPE [19] because these babies were managed prior to the publishing of the ISPAE guidelines. We attempted to reanalyse our data using the ISPAE guidelines: 7 babies were screen negative, as per the ISPAE guidelines, and screen positive as per the ESPE guidelines. Of these $7 \mathrm{ba}$ bies, 3 were found to have congenital hypothyroidism at term. None of the babies with congenital hypothyroidism identified as preterm would have been missed as per either guidelines. Thus, the new ISPAE guidelines may be more cost effective in developing countries like ours.

Our study is not without limitations. Aetiological profiling was possible in 8 out of 15 cases due to logistic issues. However, the remaining 7 babies are being followed up in the thyroid clinic. We are planning a trial off therapy at 3 years of age and aetiological assessment in these infants at 3 years of age. Also, the small sample size in our study is a significant limitation.

To summarise, we have described the experience of our unit in screening and evaluating preterm babies for congenital hypothyroidism. We observed a high prevalence (1 in 77). A need for repeat venous testing, irrespective of initial screening, and significant permanent congenital hypothyroidism (50\%) were observed in our series. 


\section{References}

1. Manglik AK, Chatterjee N, Ghosh G. Umbilical cord blood TSH levels in term neonates: A screening tool for congenital hypothyroidism. Indian Pediatr 2005; 42: 1029-1032.

2. Prabhu SR, Mahadevan S, Jagadeesh S, Suresh S. Congenital Hypothyroidism: Recent Indian data. Indian J Endocrinol Metab 2015; 19: 436-437. doi: 10.4103/2230-8210.152800.

3. Kaur G, Srivastav J, Jain S, et al. Preliminary report on neonatal screening for congenital hypothyroidism, congenital adrenal hyperplasia and glucose-6-phosphate dehydrogenase deficiency: a Chandigarh experience. Indian J Pediatr 2010; 77: 969-973. doi: 10.1007/s12098-010-0150-x.

4. Gopalakrishnan V, Joshi K, Phadke S, et al. Newborn Screening for Congenital Hypothyroidism, Galactosemia and Biotinidase Deficiency in Uttar Pradesh, India. Indian Pediatr 2014; 51: 701-705.

5. Rama Devi AR, Naushad SM. Newborn screening in India. Indian J Pediatr 2004; 71: 157-160. doi: 10.1007/BF02723099.

6. Lafranchi S. Hypothyroidism. In: Behrman RE, Kleigman RM, Jenson HB (eds.). Nelson Textbook of Pediatrics. 17th ed. Saunders, Philadelphia 2004; 1872-1879.

7. Hashemipour M, Hovsepian S, Ansari A, et al. Screening of congenital hypothyroidism in preterm, low birth weight and very low birth weight neonates: A systematic review. Pediatr Neonatol 2018; 59: 3-14. doi: 10.1016/j.pedneo.2017.04.006.

8. Hyman SJ, Novoa Y, Holzman I. Perinatal endocrinology: common endocrine disorders in the sick and premature newborn. Endocrinol Metab Clin North Am 2009; 38: 509-524. doi: 10.1016/j. ecl.2009.06.005.

9. Srinivasan R, Harigopal S, Turner S, Cheetam T. Permanent and transient congenital hypothyroidism in preterm infants. Acta Pediatr 2012; 101: e179-182. doi: 10.1111/j.1651-2227.2011.02536.x.

10. Mao HQ, Yang RL, Liu ZH. Correlation of congenital hypothyroidism with birth weight and gestational age in newborn infants. Zhejiang Da Xue Xue Bao Yi Xue Ban 2007; 36: 378-381.

11. Tylek-Lemańska D, Kumorowicz-Kopiec M, Starzyk J. Screening for congenital hypothyroidism: the value of retesting after four weeks in neonates with low and very low birth weight. J Med Screen 2005; 12: 166-169. doi: 10.1258/096914105775220697.

12. Bijarnia S, Wilcken B, Wiley VC. Newborn screening for congenital hypothyroidism in very-low-birth-weight babies: the need for a second test. J Inherit Metab Dis 2011; 34: 827-833. doi: 10.1007/ s10545-011-9286-8.

13. Korada M, Pearce MS, Ward Platt MP, et al. Repeat testing for congenital hypothyroidism in preterm infants is unnecessary with an appropriate thyroid stimulating hormone threshold. Arch Dis Child Fetal Neonatal Ed 2008; 93: F286-F288. doi: 10.1136/adc.2007.134999.
14. Tylek-Lemańska D, Kumorowicz-Kopiec M, Starzyk J. Screening for congenital hypothyroidism: the value of retesting after four weeks in neonates with low and very low birth weight. J Med Screen 2005; 12: 166-169. doi: 10.1258/096914105775220697.

15. Vigone MC, Caiulo S, Di Frenna M, et al. Evolution of thyroid function in preterm infants detected by screening for congenital hypothyroidism. J Pediatr 2014; 164: 1296-1302. doi: 10.1016/j. jpeds.2013.12.048.

16. Kugelman A, Riskin A, Bader D, Koren I. Pitfalls in screening programs for congenital hypothyroidism in premature newborns. Am J Perinatol 2009; 26: 383-385. doi: 10.1055/s-0028-1110091.

17. Delange F, Dalhem A, Bourdoux $P$, et al. Increased risk of primary hypothyroidism in preterm infants. J Pediatr 1984; 105: 462-469. doi: 10.1016/s0022-3476(84)80030-x.

18. American Academy of Pediatrics, Rose SR; Section on Endocrinology and Committee on Genetics, American Thyroid Association, Brown RS; Public Health Committee, Lawson Wilkins Pediatric Endocrine Society, Foley T, Kaplowitz PB, Kaye Cl, Sundararajan S, Varma SK. Update of newborn screening and therapy for congenital hypothyroidism. Pediatrics 2006; 117: 2290-2303. doi: 10.1542/ peds.2006-0915.

19. Léger J, Olivieri A, Donaldson M, et al.; ESPE-PES-SLEP-JSPEAPEG-APPES-ISPAE; Congenital Hypothyroidism Consensus Conference Group. European Society for Paediatric Endocrinology consensus guidelines on screening, diagnosis, and management of congenital hypothyroidism. J Clin Endocrinol Metab 2014; 99 : 363-384. doi: 10.1210/jc.2013-1891.

20. Silva SA, Chagas AJ, Goulart EM, et al. Screening for congenital hypothyroidism in extreme premature and/or very low birth weight newborns: the importance of a specific protocol. J Pediatr Endocrinol Metab 2010; 23: 45-52. doi: 10.1515/jpem.2010.23.1-2.45.

21. Zhou J, Luo J, Lin J, et al. Perinatal risk factors for congenital hypothyroidism: A retrospective cohort study performed at a tertiary hospital in China. Medicine (Baltimore) 2020; 99: e20838. doi: 10.1097/ MD.0000000000020838.

22. Desai MP, Sharma R, Riaz I, et al. Newborn screening guidelines for congenital hypothyroidism in India: recommendations of the Indian society for pediatric and adolescent endocrinology (ISPAE) - Part I: Screening and confirmation of diagnosis. Indian J Pediatr 2018; 85 : 440-447. doi: 10.1007/s12098-017-2575-y.

23. Sudhanshu S, Riaz I, Sharma R, et al. Newborn Screening Guidelines for Congenital Hypothyroidism in India: Recommendations of the Indian Society for Pediatric and Adolescent Endocrinology (ISPAE) - Part II: Imaging, Treatment and Follow-up. Indian J Pediatr 2018; 85: 448-453. doi: 10.1007/s12098-017-2576-x. 